\title{
VIDA PRIVADA, INTIMIDADE E DADOS PESSOAIS VEICULADOS NA INTERNET
}

\section{PRIVATE LIFE, INTIMACY AND PERSONAL DATA APPEARED ON THE INTERNET}

\author{
${ }^{1}$ Alessandra Depieri Viegas \\ ${ }^{2}$ Luana da Costa Leão
}

\section{RESUMO}

As recentes tecnologias alteraram a forma de socialização do ser humano, culminando em uma imersão no mundo virtual cada vez maior da pessoa humana. Essa transformação no mundo dos conceitos faz com que o virtual passe a ter repercussão direta no mundo real, no qual a vida privada é cada vez mais exposta nos meios virtuais. Utiliza-se o método hipotético- dedutivo a fim de verificar se a presente legislação acompanha a velocidade das transformações ocorridas no mundo virtual e esse descompasso pode deixar a pessoa desprotegida principalmente em relação aos seus direitos à intimidade, privacidade e a própria dignidade humana.

Palavras chaves: Direito Digital. Vida Privada. Intimidade. Dados Pessoais.

\begin{abstract}
ABSTRAT
Recent technologies have changed the way of socialization of human beings, culminating in an immersion in the virtual world increasingly of the human person. This transformation in the world of concepts makes the virtual pass to have a direct impact in the real world, in which private life is increasingly exposed in virtual environments. We use the hypothetical- deductive method to monitor whether this legislation keep pace with the changes occurring in the virtual world and this mismatch can leave unprotected person especially in relation to their rights to intimacy, privacy and human dignity itself.
\end{abstract}

Keywords: Digital Law, Private Life, Intimacy, Personal Data.

\footnotetext{
${ }^{1}$ Aluna do Programa de Mestrado em Direito Negocial pela Universidade Estadual de Londrina -UEL, Paraná, (Brasil). Advogada. E-mail: alessandradviegas@ hotmail.com

${ }^{2}$ Aluna do Programa de Mestrado em Direito Negocial na Universidade Estadual de Londrina - UEL. Advogada.

E-mail: luanaleao.adv@outlook.com
} 


\section{INTRODUÇÃO}

As modificações na sociedade são periódicas e as ciências sociais aplicadas, particularmente o Direito, devem estar sempre cautelosas a fim de acompanhar um cenário em constante mudança, o qual é determinado por uma revolução tecnológica concentrada nas tecnologias de comunicação e informação.

Considerando essa evolução na tecnologia da informação, tem se observado muitos casos de afronta ao direito à intimidade na internet. A liberdade e facilidade com que as pessoas se expressam em virtude do desenvolvimento das tecnologias da informação fizeram com que em diversas situações limites fossem ignorados.

O presente artigo tem como finalidade um estudo sobre como os direitos à vida privada e à intimidade se relacionam com a temática da proteção dos dados e registros pessoais que circulam na internet. $\mathrm{O}$ contexto histórico que dá azo à pesquisa se concretiza no espantoso crescimento da internet como meio de interação social que propicia o relacionamento interpessoal e, cada vez mais, o comércio de bens e serviços em ambiente virtual, o que exige a transmissão de dados entre o usuário e seus fornecedores e o armazenamento dos registros de conexão e de acesso às aplicações.

Utiliza-se como marco teórico a edição do Marco Civil da Internet (Lei $n^{\circ}$. 12.695/2014), e do Decreto $n^{\circ}$. 8.771/2016 que tiveram a finalidade de estabelecer parâmetros e diretrizes para a utilização dos dados e registros pessoais, com vistas a impedir a utilização maciça, indiscriminada e abusiva de tais informações.

Ao perseguir tal objetivo, a pesquisa pode ser qualificada como hipotético-dedutiva, em que se parte de uma hipótese de trabalho e, então, contextualizando-a, atingem-se os resultados almejados, qual seja, identificar a importância do Marco Civil da Internet e do Decreto 8.771/2016 no que diz respeito à vida privada, à intimidade e aos dados pessoas veiculados na internet, abordando os novos caracteres da sociedade na era digital e as consequências jurídicas de tal evolução.

O presente trabalho será dividido pelos seguintes itens: o direito fundamental à vida privada e à intimidade; os dados e registros pessoais na internet; o Marco Civil da Internet e o Decreto $n^{\circ} .8 .771 / 2016$ e o sigilo de dados na rede. 


\section{O DIREITO FUNDAMENTAL À VIDA PRIVADA E À INTIMIDADE}

$\mathrm{O}$ estudo parte de uma breve síntese sobre o direito fundamental à vida privada e à intimidade a fim de verificar como essa garantia de âmbito constitucional se relaciona com as informações que transitam na internet e que dizem respeito aos usuários, antes de dedicar-se à temática da proteção e do sigilo de registros e dados pessoais que veiculam na rede.

A vida privada e a intimidade são direitos fundamentais consagrados na Constituição Federal por meio do artigo $5^{\circ}$, inciso $\mathrm{X}$, constituem também atributos inatos à personalidade humana. Os direitos da personalidade são inatos, mas cabe ao Estado reconhecer tais direitos e positivá-los, em nível constitucional ou por meio da legislação ordinária para que possam ser opostos contra o arbítrio do poder público ou dos particulares em geral (BITTAR, 1989, p. 211).

Enfatiza-se que existe uma grande dificuldade para conceituar e delimitar o que seriam os direitos de vida privada e de intimidade, principalmente por conta das oscilações morais que circundam esses valores e das mudanças sociais e culturais que os afetam frequentemente e que acabam por alterar o que se entende por vida privada e intimidade e o que deve ser tutelado da publicidade.

O direito à vida privada e à intimidade pode ser traduzido na ideia de uma parcela de nossa vida que desejamos ocultar de nossos semelhantes, na medida em que temos uma noção daquilo que é privado ou íntimo. (VIEIRA, 2002, p. 207)

Cabe mencionar o direito à vida privada e à intimidade serve como ideal de concretização da dignidade da pessoa humana. Gilberto Haddad Jabur (2000, p. 253), menciona a importância de garantir o direito à privacidade e à intimidade da pessoa humana, uma vez que, é na intimidade que o indivíduo se constrói. .

Frequentemente utiliza-se a expressão vida privada como sinônimo de privacidade e intimidade, contudo, para o Direito não se equivalem, tendo em vista que a privacidade seria o gênero do qual pertencem o direito à intimidade e o direito ao segredo. Desta feita, indispensável se faz assinalar as diferenças das duas definições que, na habitualidade, muitas vezes, são entendidas como sinônimas, mas que na realidade possuem definições e extensões diversas.

Ressalta-se do mesmo modo a distinção que alguns doutrinadores apresentam entre os conceitos de vida privada e de intimidade, em razão da realidade de que o texto constitucional, em seu artigo $5^{\circ}$, inciso X, nos apresenta os dois vocábulos. No entanto maior parte da doutrina 
os trata como sinônimos ou como sendo a vida privada gênero do qual a intimidade é espécie. Vejamos alguns posicionamentos.

A intimidade é o domínio do exclusivo que alguém reserva para si, sem nenhuma repercussão social, e ao alcance da sua vida privada que, por mais isolada que seja, é sempre um viver entre os outros seja na família, no trabalho, no lazer comum. Não há um conceito absoluto de intimidade, porém é possível identificá-la como sendo o diário íntimo, o segredo sob juramento, as próprias convicções, as situações indevassáveis de pudor pessoal, o segredo íntimo cuja mínima publicidade constrange. (FERRAZ, 2003, p. 147).

Diante de tais constatações, Pontes de Miranda (2000, p.209) entende como direito à intimidade aquele que objetiva:

Resguardar as pessoas dos sentidos alheios, principalmente da vista e dos ouvidos de outrem; pressupõe ingerência na esfera íntima da pessoa através de espionagem e divulgação de fatos íntimos obtidos ilicitamente. [...] Seu fundamento é o direito à liberdade de fazer e não fazer.

Visto que para Sônia Aguiar do Amaral Vieira (2002, p. 132) a diferença entre os conceitos de vida privada e de intimidade está na extensão e intensidade de tais prerrogativas:

[...] a vida privada, como direito garantido constitucionalmente, é a esfera menos íntima do ser humano; é o direito de subtrair do conhecimento alheio fatos de sua vida particular, bem como impedir-lhes a divulgação. Porém a natureza destes fatos não revela aspectos extremamente reservados; aspectos, portanto, que não falam tão de perto ao espírito.

A intimidade, também um direito consagrado pela nossa Constituição Federal, é a esfera mais reservada de uma pessoa. Consiste, também, na prerrogativa de excluir do conhecimento de terceiros fatos que não deseja ver expostos à publicidade alheia. No âmbito da intimidade, porém, a natureza destes fatos é revestida de um caráter muito mais sigiloso, mais reservado.

Com base nessa premissa é possível concluir que a violação da intimidade é mais grave que a violação à vida privada e, portanto, a tutela jurisdicional para aquela deve se revestir de um caráter mais severo, haja vista que o bem jurídico expira maior relevância.

A vida privada e a intimidade poderiam ser classificadas em três esferas, sendo a primeira esfera relacionada com a vida privada e sendo formada pelos acontecimentos e comportamentos que não devem se tornar de conhecimento público, mas que são compartilhados com os grupos de indivíduos mais próximos, a segunda seria a esfera da intimidade ou esfera confidencial que se constitui pelas conversações e acontecimentos que o indivíduo compartilha apenas com as pessoas sobre as quais expira relativa confiança e, por fim, a esfera do segredo, sobre a qual se protege a indiscrição e que se forma pela parcela de acontecimentos que o indivíduo guarda para si em segredo. (VIEIRA, 2002, p. 132) 
De acordo com as lições de Celso Ribeiro Bastos e Ives Gandra Martins (1989, p. 178) a tutela da vida privada:

[...] consiste na faculdade que tem cada indivíduo de obstar à intromissão de estranhos na sua vida familiar e privada, assim como de impedir-lhes o acesso a informações sobre a privacidade de cada um, e também impedir que sejam divulgadas informações sobre esta área da manifestação existencial do ser humano.

Neste contexto, o Estado carece promover aos indivíduos a proteção da parcela de sua existência em relação à publicidade e ao conhecimento alheio e essa tutela deve se dar em todos os ambientes de vivência humana, ou seja, estende-se ao ambiente virtual onde as pessoas se relacionam entre si e que também expira uma preocupação com o sigilo, com a privacidade e com o segredo.

A privacidade e a internet não são realidades diferentes, principalmente quando o assunto é a veiculação de dados e registros pessoais. Neste sentido, Tarcisio Teixeira (2015, p. 134) esclarece que a privacidade na internet pode ser violada facilmente em decorrência da indiscriminada captação de dados, comercializadas a partir da formação de perfis dos usuários, deste modo, abre-se possibilidades de envio de inúmeras mensagens não solicitadas, contexto este que ainda dá margem a outras questões jurídicas relacionadas e os prejuízos causados aos usuários, pessoas físicas ou jurídicas.

Desta forma, por analogia, podemos classificar a internet como um dos meios de comunicação em massa, bem como consequentemente, podem-se aplicar os conceitos de privacidade e intimidade aos dados envolvidos no ciberespaço.

O chamado ciberespaço é distinto do espaço físico, segundo Ricardo Lorenzetti (2004, p.29-30), bem como é um mero facilitador do incremento quantitativo do meio no qual se tornam possíveis as conhecidas vendas à distância realizadas na internet, que denominam-se de comércio eletrônico.

Com o avanço tecnológico, os atentados à intimidade e à vida privada, por meio da rede mundial de computadores, tornaram-se muito comuns. Não raro determinadas empresas obtêm dados pessoais do usuário com o propósito de ofertar os seus produtos, veiculando a sua publicidade por meio indesejáveis, o que acarreta uma ofensa à intimidade e à vida privada. (GAGLIANO, PAMPLONA FILHO, 2003, p. 106).

No dizer de Têmis Limberger (2007, p. 196), com as inovações, o que diz respeito aos bancos de dados é a grande questão que os juristas enfrentam, bem como a necessidade de 
garantir a efetividade dos direitos fundamentais, em geral, e da intimidade diante do fenômeno informático.

Com base nesse contexto virtual, o Marco Civil da Internet (Lei $\mathrm{n}^{\circ}$. 12.965), sancionado em 23 de abril de 2014, é considerado, no Brasil, um texto pioneiro a fundar direitos, deveres e regras no âmbito da realidade virtual. É visto, inclusive, como uma espécie de "Constituição da internet", porque regula, por meio de previsão de princípios, garantias, direitos e deveres de quem usa a rede, além da determinação de diretrizes para a atuação do Estado, as relações em âmbito virtual (TEIXEIRA, 2014, p. 89).

Ademais, o Marco Civil da Internet possui em sua totalidade como legislação a importância de abordar as relações que se estabelecem em rede; direitos pessoais como a inviolabilidade da vida privada e da intimidade; o sigilo no fluxo de comunicações pela internet; a garantia da privacidade e da liberdade de expressão como instrumento para o pleno exercício da cidadania, entre outros. (LUCCA; SIMÃO FILHO; LIMA, 2015, p. 249)

É claro que o texto constitucional já se aplicava imperativamente à internet, no entanto as especificidades das relações virtuais exigiam uma disciplina que comtemplasse conceitos aos instrumentos da rede e que visasse uma equivalência entre a liberdade de expressão, principalmente no que se relaciona com a publicidade, e o respeito ao sigilo de algumas informações que afetam os usuários da rede.

A Lei $n^{\circ} .12 .965 / 2014$ estabeleceu, por exemplo, em relação aos dados pessoais e aos registros de conexão e de acesso a aplicações de internet, que estes só poderiam ser transmitidos a terceiros mediante expressa e livre autorização do usuário, ou seja, a transmissão dessas informações depende, agora, da manifestação de uma concordância do usuário, sem a qual possuem caráter sigiloso, isso significa dizer que um dado lançado na internet não o torna, automaticamente, um dado público.

Além disso, a norma jurídica determina também que as empresas veiculem aos seus usuários as informações acerca da coleta, uso, armazenamento, tratamento e sistema protetivo dos dados pessoais de forma clara, o que possibilita ao usuário a escolha em se relacionar com esta ou aquela empresa de acordo com a sua maior ou menor preocupação com o tratamento que venha a ser dado aos seus dados e registros a serem repassados.

É preciso destacar também que alcançada à finalidade da utilização dos dados pessoais estes deverão ser excluídos, salvo quando a guarda de tais registros for obrigatória, casos que serão abordados mais adiante. 
Dessa forma, verifica-se que a tutela da privacidade e da intimidade ganhou novo relevo no âmbito da internet que passa a ser entendido como um ambiente em que deve se preservar certo sigilo, de acordo com a manifestação de vontade do usuário, o que nos leva a rechaçar uma crença de que a internet é um canal de publicidade em que qualquer dado ou registro ali lançado já é acompanhado de uma renúncia tácita ao direito de sigilo.

\section{OS DADOS E REGISTROS PESSOAIS NA INTERNET}

Preliminarmente ao estudo da disciplina do tratamento de dados e registros pessoais que são veiculados na internet, se faz necessário definir o que é um dado pessoal na rede e que, intuitivamente, presumimos referir-se a um dado que possa identificar, de alguma forma, uma pessoa ou um grupo de pessoas.

Na tentativa de nos apresentar um conceito de dado pessoal, destacam-se as definições adotadas pela lei italiana e pela lei suíça. Sendo aludido na lei italiana como dados pessoais os que permitem identificar a origem racial e étnica, as convicções religiosas, filosóficas ou de outros gêneros, as opiniões políticas, a adesão a partidos, sindicatos associações ou associações ou de caráter religioso, filosófico ou político ou sindical, ainda os dados pessoais aptos a revelarem o estado de saúde e a vida sexual. Assim como, na lei suíça, o dado pessoal é considerado exclusivamente no que compete ao uso pessoal. (NORI, 2015, p. 114)

As informações veiculadas em rede podem ser apresentadas em registros com dados pessoais e registros anônimos, os primeiros seriam aqueles que permitem a associação de um indivíduo de forma direta ou indireta, por sua vez, os registros anônimos são aqueles que não permitem essa associação e que perfazem apenas informações numéricas ou de valor estatístico. Apenas os registros com dados pessoais merecem a tutela do sigilo. (NORI, 2015, p. 114).

O Decreto $\mathrm{n}^{\circ}$. 8.771/2016 conceituou como dado pessoal todo dado relacionado à pessoa natural identificada ou identificável, inclusive números identificadores, dados locacionais ou identificadores eletrônicos, quando estes estiverem relacionados a uma pessoa.

Ponderadas essas considerações sobre o que se entende por dado ou registro pessoal veiculado na rede, é necessária uma reflexão sobre a publicidade de tais informações entre as empresas atuantes na internet, analisando a formação de perfis de usuários para o oferecimento de produtos de consumo e a transmissão de tais dados entre empresas para a finalidade de estudo de mercado, lançamento e direcionamento de bens ou serviços. 
Desta feita, passa-se a mencionar a subordinação ao critério de utilidade que a publicidade dos dados pessoais que veiculam na rede, ou seja, sua transmissão precisa se dar de acordo com a necessidade dessa informação, respeitando os limites da vida privada e da intimidade. Porquanto a proteção da intimidade e da vida privada, como problema real, necessita ser efetiva na internet. Na rede, o usuário fornece dados de sua vida pessoal e estes são manejados ao gosto de empresas que estão na internet e, até mesmo, de provedores. O uso dos dados pessoais pode convir a variados fins como marketing, políticos e até persecutórios, quando se vislumbra que o usuário faz parte de alguma minoria e ocorre a discriminação (VIEIRA, 2002, p. 227)

O dado pessoal veiculado na rede passa a constituir uma problemática social quando se presta a ser utilizado sem o consentimento do usuário para formar perfis com o objetivo de criar grupos vulneráveis ao consumo de produtos, de acordo com sua idade, gênero, profissão, local de residência e outras informações obtidas, o que resulta na criação de padrões de oferecimento de produtos.

Nessa situação a utilidade do dado pessoal lançado na rede se desvirtua da necessidade em relação ao propósito do usuário na internet como, a compra de um produto ou a obtenção de alguma informação relevante, e passa a ter a finalidade de formação de grupos de consumo, de acordo com suas preferências denotadas.

Além disso, a comercialização de tais dados constituía uma realidade frequente, principalmente por que não havia nenhuma política de privacidade que estabelecesse regras acerca da captação, tratamento e transmissão de tais dados, ou seja, o usuário estava condicionado à política adotada pela empresa de forma arbitrária.

De acordo com as lições de Tarcisio Teixeira (2015. P. 122) os dados pessoais inseridos na rede possuem a mesma proteção de sigilo que a correspondência, e sua inviolabilidade está ligada a privacidade do usuário, leciona o autor:

O sigilo da comunicação significa a liberdade de comunicação por qualquer veículo oferecido pela tecnologia moderna, alcançando, inclusive, as áreas da telecomunicação e telegráfica. Com relação ao sigilo dos dados, quer dizer que os dados e as informações sobre pessoas são protegidos, sendo inviolável o acesso a eles.

No entanto, tais concepções esbarram na tutela da liberdade de expressão que tem como viés a utilização de informações da rede acerca de usuários para a manifestação que contemplem o envio de mensagens de consumo, o estudo de preferências deste ou daquele usuário para o oferecimento de produtos e serviços e mesmo o direcionamento de conteúdos 
para os indivíduos que, pelos dados fornecidos na rede, demonstrem alguma afinidade a ser explorada.

No entanto, vislumbra-se ainda que a liberdade de expressão que circunda a veiculação de dados pessoais em rede pode acarretar prejuízos à privacidade assim como a privacidade pode acarretar prejuízos à liberdade de expressão.

Neste contexto, Tarcisio Teixeira (2015, p. 322) alerta para a possibilidade de conflito entre tais direitos fundamentais:

Notadamente quanto ao envio de mensagens eletrônicas, se, por um lado, isso não pode deixar de ser considerada manifestação da liberdade de expressão por parte do remetente; por outro, é uma invasão da privacidade do destinatário. Nasce disso um confronto de direitos que, eventualmente, poderia ser objeto de uma norma, a fim de equilibrá-los no campo da internet.

Apresentando a realidade do direito comparado, remete-se à experiência da União Européia, onde a regra é que os dados pessoais veiculados na rede sejam apagados após atingirem sua finalidade e só poderão ser retidos e transmitidos em casos de consentimento expresso do usuário aos provedores ou nos casos de investigação criminal. (TEIXEIRA, 2015, p. 322).

Insta mencionar a preocupação com a destinação que é dada aos dados pessoais e registros, que, via de regra, possui fins empresariais, que objetivam o aumento do consumo, e fins sociais ou políticos que podem resultar, ainda em métodos de controle e de vigilância. $\mathrm{O}$ uso de dados pode implicar no risco à privacidade e à neutralidade das decisões do usuário. (LUCCA; SIMÃO FILHO; LIMA, 2015, p. 327)

Dessa forma, a realidade social de indiscriminada utilização e transmissão de dados pessoais e registros de acesso ou de conexão dos usuários, que acarreta prejuízos à privacidade e a intimidade dos usuários, exigia um regramento legal sobre os limites de atuação das empresas entre o sigilo de informações e a liberdade de expressão na rede.

\section{O Marco Civil da Internet}

Sem dúvida, a maior inspiração da legislação de regramento da internet que vem nascendo no Brasil - tema sobre o qual já podemos citar a Lei no ${ }^{\circ} .12 .965 / 2014$, Marco Civil da Internet, e o Decreto $\mathrm{n}^{\circ} .8 .771 / 2016$ - tem sua origem com vistas a coibir abusos, preservar interesses e direitos dos usuários, proteger a vida privada e a intimidade e impedir a utilização 
da internet para fomentar a prática dos mais variados delitos que ganham amplitude em rede como, por exemplo, a espionagem empresarial e a pedofilia.

Sob essas premissas a Lei $\mathrm{n}^{\circ}$. 12.965/2014 consagrou o direito de acesso à internet como essencial ao exercício da cidadania; a proteção da privacidade como regra principiológica, a proteção de dados pessoais, a inviolabilidade da intimidade e da vida privada; a inviolabilidade e o sigilo do fluxo de comunicações e a garantia do direito à liberdade de expressão.

Diante desse regramento, inédito na legislação pátria, as exigências de condutas empresariais frente aos usuários passam a ter novos contornos, motivo pelo qual (LUCCA; SIMÃO FILHO; LIMA, 2015, p. 321) nos faz refletir acerca do que denomina de "paradoxo decorrente da utilização dos dados maciços" e explica:

[...] gera-se um paradoxo que se relaciona ao caminho empresarial que vem sendo
trilhado em ambiente de internet, decorrente da forma de utilização dos dados maciços
produzidos a cada segundo e da possibilidade de sua captação, verificação,
classificação e utilizaçãa, sem que se afete estes direitos assegurados ao cidadão.
O paradoxo refere-se exatamente ao contexto da privacidade. Por um lado a lei
determina a sua estrita proteção. A outro, os agentes que operam a internet conseguem,
a partir da análise dos dados maciços colhidos, obter mais fiel retrato da pessoa, suas
atividades, gostos, tendências, idade, formação, nível socioeconômico, esportes de
preferência, lazer e etc.

A Lei $n^{\circ} .12 .965 / 2014$, trouxe para o contexto brasileiro que o tratamento de dados e registros pessoais dos usuários deve atender ao critério de utilidade, ou seja, os dados solicitados devem guardar correspondência com a finalidade de sua exigência (compra de produtos, utilização de serviços e etc.), não se prestando a formação de cadastros a serem utilizados para a formação de perfis e padrões de consumo.

Por meio de seu artigo $7^{\circ}$, incisos VII e X o Marco Civil da Internet estabeleceu que é direito do usuário que seus dados pessoais, registros de conexão e de acesso às aplicações de internet não sejam fornecidos a terceiros sem que haja sua expressa e livre autorização, bem como, facultou a este o requerimento de exclusão definitiva dessas informações após atingida a sua utilidade, o que impede o bombardeio do internauta com propagandas de produtos e oferecimento de serviços com base no seu histórico de navegação.

Além disso, disciplinou algumas situações acerca da guarda de registros após alcançada a finalidade da utilização, essas situações são as seguintes: os registros de guarda obrigatória, os registros de guarda necessária, os registros de guarda vedada e os registros de guarda autorizada. 
Os registros de guarda obrigatória estão disciplinados no artigo 13 e no artigo 15 do Marco Civil da Internet e a finalidade dessa obrigatoriedade é facilitar a apuração de ilícitos e a não obediência a essa guarda pode ensejar a responsabilização civil e criminal.

Os dispositivos mencionados determinam que o administrador do sistema autônomo deve guardar, pelo prazo de 1 (um) ano, os registros de conexão; e que o provedor de aplicações de internet deve guardar, pelo prazo de 6 (seis) meses, os registros de acesso a aplicações da internet. Tal armazenamento deve se dar sob a proteção de sigilo e em ambiente controlado e seguro.

Os registros de guarda necessária se prestam a provar os atos e operações realizadas na internet, estão elencados no artigo $7^{\circ}$ do Marco Civil da Internet e se relacionam com as regras gerais do comércio.

Fábio Nori (2015, p. 127) explana que "a coleta e processamento desses registros, dentro dos limites, ao ato ao qual estão associados, independe de qualquer autorização e são intrínsecos à prestação do serviço."

Os registros de guarda proibida foram definidos pelo Marco Civil da Internet levando em conta o risco excessivo que sua divulgação acarreta para a garantia da privacidade do usuário, a vedação inserida na lei funciona como uma tutela preventiva e possui também caráter irreversível e específico.

Tais disciplinas estão elencadas no artigo 14 e 16 da Lei $n^{\circ}$. 12.956/2014, que estabelecem que na provisão de conexão é proibida a guarda dos registros de acesso às aplicações de internet e na provisão de aplicações da internet é vedada a guarda de registros de acesso sobre os quais não haja consentimento do usuário ou de dados pessoais excessivos em relação a finalidade, quando haja consentimento do usuário.

Os registros de guarda autorizada são aqueles em que se exige a expressa autorização do usuário e são vinculados a algumas finalidades específicas das empresas que o solicitam, normalmente ligadas à análise comportamental para o oferecimento de produtos e serviços.

É necessário destacar que a legislação pátria não veda o estudo de mercado por meio dos registros e dados da rede, o que fomenta as estatísticas de consumo e propicia a melhora na oferta de produtos e serviços, bem como, não impede a propaganda no âmbito da internet direcionada a este ou aquele usuário, de acordo com suas preferências. No entanto condiciona essa atuação empresarial à vontade do usuário, que possui o direito de optar por integrar ou não a formação de perfis de consumo e não ser alvo de propagandas de produtos e serviços inconvenientes. 
Essas diretrizes visam resguardar ao usuário as escolhas sobre como sua atuação na rede pode se tornar instrumento das empresas que atuam no mercado da internet e conferem a este o poder se ser alvo ou não de uma publicidade maciça, de escolher quais produtos e quais serviços deseja que lhe sejam oferecidos e quando essa oferta deve cessar.

\section{O sigilo de Dados e o Decreto no ${ }^{\circ}$ 8.771/2016}

O Decreto $n^{\circ}$. 8.771/2016, de 11 de maio de 2016, é a legislação mais recente acerca da forma como os dados pessoais devem ser tratados no âmbito da internet e teve a função de regulamentar aspectos que já haviam sido integrados ao ordenamento jurídico por meio do Marco Civil da Internet, mas que necessitavam de disciplina mais específica.

Os objetivos do Decreto $\mathrm{n}^{\circ}$. 8.771/2016, conforme disposição do artigo, são discriminação de pacotes de dados; degradação de dados; proteção de dados por provedores; requisição de dados pela administração pública; fiscalização e apuração de infrações. Destacase que as disposições deste diploma legal não se aplicam aos serviços de telecomunicação que não se destinam ao provimento de conexão de internet.

No que se relaciona com a proteção dos registros, dos dados pessoais e das comunicações privadas, o Decreto $\mathrm{n}^{\circ}$. 8.771/2016 estabelece que a requisição de dados pelas instituições públicas só pode se concretizar por meio da fundamentação da competência e dos motivos para a requisição de dados pessoais.

De acordo com o artigo $11, \S 3^{\circ}$, é vedada a requisição de dados com pedidos coletivos ou genéricos, ou seja, esse diploma legal teve a preocupação de resguardar os dados e registros pessoais dos usuários não só em relação às empresas do comércio eletrônico, mas também em relação aos órgãos do Poder Público.

De acordo com esse marco legislativo os provedores de conexão e aplicação devem reter a menor quantidade possível de dados pessoais e de comunicação privadas e tais registros devem ser excluídos assim que atingida a finalidade ou expirado o prazo legal, o que se compatibiliza com o critério de utilidade que foi adotado pelo Marco Civil da Internet.

Essa legislação estabelece como dado cadastral as informações relativas à filiação, ao endereço e à qualificação pessoal (nome, prenome, estado civil e profissão) e inovou ao especificar quais são os elementos de um dado pessoal veiculado na rede.

Definindo o que se entende por tratamento de dados pessoais, tal decreto, enquadra como toda operação realizada com dados pessoais, como as que se referem à coleta, produção, 
recepção, classificação, utilização, acesso, reprodução, transmissão, distribuição, processamento, arquivamento, armazenamento, eliminação, avaliação ou controle da informação, modificação, comunicação, transferência, difusão ou extração.

Acerca dos padrões de segurança para o sigilo dos registros, dados pessoais e comunicações privadas, o Decreto $\mathrm{n}^{\mathrm{o}}$. 8.771/2016 estabeleceu diretrizes para a guarda, armazenamento e tratamento de dados pessoais e comunicações privadas, abordadas a seguir.

Por exemplo, o controle sobre o acesso de dados, mediante a atribuição de responsabilidades às pessoas que tenham acesso e acesso exclusivo para determinados usuários, objetivando a criação de padrões de individualização e restrição das pessoas que têm acesso aos esses arquivos, a fim de posterior atribuições de responsabilidades.

Acerca do tratamento de dados e registros pessoais por funcionários de provedores, Patricia Peck Pinheiro (2013. P. 213) explica:

\begin{abstract}
A fragilidade está nas pessoas, principalmente no funcionário, seja ele próprio ou de empresa fornecedora (terceirizada), por diversos tipos de motivação, é envolvido para permitir o acesso ao ambiente (deixar a porta aberta), ou ele mesmo agir em nome de quem o contratou (pode ser coletando e enviando informações, pode ser apagando as mesmas na rede, entre outras situações). Há ainda o "laranja", que seria aquela pessoa envolvida na espionagem por ingenuidade, inocência ou até mesmo negligência.
\end{abstract}

Referido decreto exige também a previsão de mecanismos de autenticação para acesso aos registros para assegurar a individualização do acesso pelo responsável e combater a ocorrência de fraudes.

Há norma também que exige a criação de relatório com o inventário dos acessos realizados que contenham os seguintes dados: momento, duração, identidade do funcionário ou responsável e o arquivo acessado, de modo a propiciar o controle de acesso e inspecionar o uso excessivo de tais informações.

Por último, a legislação impõe também o uso de soluções de gestão dos registros para garantir a inviolabilidade dos dados, neste ponto, a legislação sugere o mecanismo de encriptação ou medidas equivalentes.

Além dessas diretrizes, o Decreto $\mathrm{n}^{\mathrm{o}}$. 8.771/2016 consagrou também o dever de publicidade em relação às informações quanto aos procedimentos de segurança e sigilo de dados que devem ser acessíveis a qualquer interessado, preferencialmente, pelos sítios eletrônicos, observada a garantia do segredo empresarial, o que permite que os usuários privilegiem as empresas que denotem maior responsabilidade com tais dados e registros. 
Tais diretrizes já representam o avanço na proteção da vida privada e da intimidade no âmbito da internet, porém o ideal de eliminação dos abusos depende de efetiva fiscalização por parte do Poder Público.

\section{Conclusão}

Com base no estudo aqui formulado, é possível concluirmos que a vida privada e a intimidade são direitos fundamentais inatos à personalidade humana e cuja tutela representa uma ferramenta para a concretização da dignidade da pessoa humana.

É possível identificarmos que a internet é um ambiente em que a tutela da privacidade e da intimidade deve encontrar respaldo concreto, não perfazendo um espaço em que os dados ali veiculados se tornam automaticamente de caráter público apenas estarem inseridos na rede.

Definimos como dados pessoais as informações capazes de identificar um indivíduo ou um grupo de indivíduos e os registros de conexão de acesso como informações do histórico de navegação do usuário, cuja transmissão afeta a esfera de privacidade e intimidade do usuário.

Destacamos a abusividade do uso indiscriminado e maciço de dados e registros pessoais dos usuários da rede para a criação de perfis de consumo e o oferecimento de produtos e serviços não solicitados e inconvenientes.

O Marco Civil da Internet, Lei $n^{\circ} .12 .965 / 2014$, foi a norma jurídica que inaugurou a tutela da vida privada e da intimidade na rede, por meio das diretrizes para o uso de dados e registros pessoais, em especial pela determinação de que a transmissão de tais informações exige expressa e livre autorização do usuário.

O Decreto $\mathrm{n}^{\circ}$. 8.771/2016 se apresenta como instrumento legislativo de materialização das diretrizes do Marco Civil da Internet por meio da criação de regras para o acesso do Poder Público aos dados e registros pessoais e criando parâmetros para o armazenamento e tratamento de tais dados e registros pelas empresas que atuam na internet.

É claro que o tratamento legal conferido pela Lei $\mathrm{n}^{\circ}$. $12.965 / 2014$ e pelo Decreto $\mathrm{n}^{\circ}$. 8.771/2016 já representa um avanço para a proteção do usuário da rede que fornece seus dados para a utilização e o acesso a produtos e serviços, no entanto a problemática exige também o desenvolvimento de políticas públicas para a conscientização de usuários e empresas do ambiente virtual com base na ética, na solidariedade e no corporativismo das relações que se desenvolvem nesse meio. 
A criação de leis específicas acerca da utilização do espaço virtual é sinal de avanço do legislador nesse campo, visando proteger o indivíduo principalmente no que se refere a sua existência, sua dignidade e seus direitos mais íntimos e pessoais.

Estabelecer os princípios legais que irão servir de norte para a legislação, como fizeram o Marco Civil da Internet e o Decreto $\mathrm{n}^{\circ}$. 8.771/2016, institui o entendimento das bases sobre as quais irá se assentar a resolução dos conflitos oriundos do mundo virtual, para os quais o Direito, ao longo da historia e da necessidade, foi invocado para tutelar.

\section{Referências Bibliográficas}

AZEREDO, JOÃO FABIO A. Sigilo das comunicações eletrônicas diante do marco civil da internet. In: DE LUCCA, NEWTON; SIMÃO FILHO, ADALBERTO; LIMA, CÍNTIA ROSA PEREIRA DE (coords.). Direito e internet III - Tomo II: marco civil da internet (Lei n. 12.695/2014). São Paulo: QuartierLatin, 2015.

\section{BASTOS, CELSO RIBEIRO; MARTINS, IVES GANDRA. Comentários à Constituição do}

Brasil. Vol. 2. São Paulo: Editora Saraiva, 1989.

BRASIL. Decreto $n^{\circ} 8.771$, de 11 de maio de 2016. Regulamenta a Lei no 12.965, de 23 de abril de 2014, para tratar das hipóteses admitidas de discriminação de pacotes de dados na internet e de degradação de tráfego, indicar procedimentos para guarda e proteção de dados por provedores de conexão e de aplicações, apontar medidas de transparência na requisição de dados cadastrais pela administração pública e estabelecer parâmetros para fiscalização e apuração de infrações. Disponível em <http://www.planalto.gov.br/ccivil_03/_Ato20152018/2016/Decreto/D8771.htm>. Consulta realizada em 02/09/2016.

BRASIL. Lei $\mathrm{n}^{\circ}$. 12.965, de 23 de abril de 2014. Estabelece princípios, garantias, direitos e deveres para o uso da Internet no Brasil. Disponível em <http://www.planalto.gov.br/ccivil_03/_ato2011-2014/2014/lei/112965.htm>.Ｃ Consulta realizada em 02/06/2016.

BITTAR, CARLOS ALBERTO. Os direitos da personalidade. Rio de Janeiro: Editora Forense Universitária, 1989. 
DE LUCCA, NEWTON; SIMÃO FILHO, ADALBERTO; LIMA, CÍNTIA ROSA PEREIRA DE (coords.). Direito e internet III - Tomo II: marco civil da internet (Lei n. 12.695/2014). São Paulo: QuartierLatin, 2015.

FERRAZ JÚNIOR, TERCIO SAMPAIO. Introdução ao estudo do direito:técnica, decisão, dominação. 4. ed., rev. e ampl. São Paulo: Atlas, 2003.

GAGLIANO, PABLO STOLZE; PAMPLONA FILHO, RODOLFO MÁRIO. Novo curso de direito civil: abrangendo o código de 1916 e o novo Código Civil (2002). 4. ed., rev. e atual. São Paulo: Saraiva, 2003-2008.

JABUR, GILBERTO HADDAD. Liberdade de pensamento e direito à vida privada: conflitos entre direitos da personalidade. São Paulo: Editora Revista dos Tribunais, 2000.

LIMBERGER, TÊMIS. Direito e informática: os desafios de proteger os direitos do cidadão. In: SARLET, INGO WOLFGANG (org.). Direitos fundamentais, informática e comunicação: algumas aproximações. Porto Alegre, RS: Livraria do Advogado, 2007.

LORENZETTI, Ricardo Luis. Comércio Eletrônico. Trad. De Fabiano Menke. São Paulo: Revista dos Tribunais, 2004.

MIRANDA, Pontes de. Sistema de ciência positiva de direito. Tomo 4. Campinas, SP: Bookseller, 2000.

NORI, FABIO. A guarda dos registros de conexão e dos registros de acesso às aplicações no marco civil. In: DE LUCCA, NEWTON; SIMÃO FILHO, ADALBERTO; LIMA, CÍNTIA ROSA PEREIRA DE (coords.). Direito e internet III - Tomo II: marco civil da internet (Lei n. 12.695/2014). São Paulo: QuartierLatin, 2015.

PINHEIRO, PATRICIA PECK. Direito digital. 5a ed. São Paulo: Saraiva, 2013.

SANTOS, ANTÔNIO JEOVÁ. Dano moral na internet. São Paulo: Método, 2001. 
TEIXEIRA, TARCÍSIO. Curso de direito e processo eletrônico: doutrina, jurisprudência e prática. $3^{\text {a }}$ ed. São Paulo: Saraiva, 2015.

VIEIRA, SONIA AGUIAR DO AMARAL. Inviolabilidade da vida privada e da intimidade pelos meios eletrônicos. São Paulo: Editora Juarez de Oliveira, 2002. 